\title{
MÉTODOS Y TÉCNICAS DE ANÁLISIS TOPONÍMICO URBANO Y SU APLICACIÓN EN LA CIUDAD DE TOLEDO
}

\author{
Ayar Rodríguez de Castro ${ }^{1}$ \\ Isabel Rodríguez Chumillas ${ }^{2}$ \\ Antonio Vázquez Hoehne ${ }^{1}$ \\ ${ }^{1}$ Centro Geo I+D. E.T.S.I. Topografía, Geodesia y Cartografía. Universidad Politécnica de Madrid. \\ ${ }^{2}$ Departamento de Geografía. Universidad Autónoma de Madrid \\ ayar.rodriguez@upm.es, isabel.rodriguez@uam.es, antonio.vazquez.hoehne@upm.es
}

\section{RESUMEN}

En este trabajo se aborda el análisis de la toponimia urbana como herramienta de información geográfica. En este sentido se propone una serie de técnicas toponímicas para el reconocimiento y la puesta en valor de la información que proporciona la toponimia en el marco urbano. El uso de observación de campo, derivas urbanas, mapas mentales y encuestas enfocado al análisis de la toponimia urbana desde una perspectiva crítica, facilita una información muy valiosa en el análisis urbano. A partir de la presentación de algunos casos de estudio, se pone de relieve la necesidad de afrontar el análisis de la toponimia desde una metodología múltiple.

Palabras clave: toponimia urbana, análisis geográfico, técnicas toponímicas.

\section{ABSTRACT}

In this work urban toponymy analysis as a geographic information tool is addressed. Some techniques for the recognition and valuation of the information provided by place names in urban frame are proposed. The use of field work, urban derives, mental maps and surveys focused on the analysis of urban toponymy from a critical scope, provides very useful information in urban analysis. Some case studies are presented, through which it is highlighted the importance of analyzing toponymy from a multimethodological perspective.

Keywords: urban toponymy, geographical analysis, toponymic techniques.

Fecha de recepción: diciembre 2015.

Fecha de aceptación: octubre 2016. 


\section{LA TOPONIMIA EN EL ANÁLISIS GEOGRÁFICO}

El estudio de la toponimia tradicionalmente ha suscitado interés en el campo de la Geografía, aunque no siempre se le ha prestado la atención necesaria. Con frecuencia los nombres de lugar se han utilizado como herramienta auxiliar en la explicación de la historia de los lugares y no como el campo de conocimiento que constituyen. En el análisis geográfico, la consideración del valor de la toponimia como objeto de estudio per se es un fenómeno reciente, por lo que no es de extrañar que las experiencias existentes en el desarrollo y aplicación de metodologías empíricas para su análisis sean escasas y, con frecuencia, centradas exclusivamente en el análisis etimológico y semántico de los topónimos. En este trabajo se abordarán algunas propuestas de uso y aplicación de herramientas y metodologías tradicionales dentro del giro epistemológico que está experimentando el campo de la toponimia en los últimos años.

Para la Geografía, la toponimia tiene interés en una triple dimensión (Rodríguez, 2012). En primer lugar, los topónimos constituyen los identificadores espaciales de referencia para el conjunto de los ciudadanos. En segundo lugar, los nombres de lugar tienen una importancia capital como instrumentos para la conservación y difusión de la información geográfica. Por último, cada topónimo contiene información sobre el lugar al que designa, tanto por su significado como por su contexto, su origen y su evolución. Esta última cuestión supone que la toponimia tenga un indiscutible valor patrimonial inmaterial (UNGEGN, 2011) y un especial interés en el análisis geográfico (Riesco, 2010), donde los nombres de lugar pueden erigirse en instrumentos informativos del territorio (Tort, 1999) tanto a través de su análisis lingüístico como por la información que proporcionan sobre cada lugar (Rodríguez y Vázquez, 2013).

El valor de la toponimia como herramienta del territorio es su función menos estudiada y explotada por la ciencia geográfica. Geógrafos como Vidal de la Blache o Sauer pusieron de manifiesto en repetidas ocasiones la importancia de la toponimia y sus implicaciones en el análisis del territorio (Ordinas y Binimelis, 2013), pero no fue hasta mediados del siglo pasado cuando autores como Dorion (1984) comenzaron a trabajar en la construcción de una base epistemológica para el estudio de la toponimia en el análisis geográfico. Los primeros estudios sobre el valor geográfico de los topónimos se centraron fundamentalmente en el análisis del contenido lingüístico de los nombres de lugar y su transparencia, en definitiva la información que se puede extraer del nombre con su mera lectura. En el caso de España, donde el interés por el estudio de la toponimia experimentó un cierto retraso con respecto a otros países (Arroyo, 2010; Ordinas y Binimelis, 2013), estos primeros trabajos se corresponden con las aportaciones de lingüistas y filólogos como Coromines o Moreu-Rey.

En los años 80-90, la Geografía comenzó también a interesarse por la función de los topónimos como etiquetas que contienen información sobre el lugar en la medida en que cada nombre geográfico se corresponde con un contexto físico y social específico. Trabajos como los de Joan Tort (Tort, 2001; 2003) son ilustrativos de la utilidad que tiene el análisis del contexto toponímico en el estudio de los paisajes, ya que los topónimos forman parte del paisaje y participan activamente en su conceptualización.

En un nuevo giro epistemológico, en la última década se está abriendo camino una nueva línea de investigación en toponimia. Se trata de una aproximación metasemántica que aboga 
por concentrarse no en el estudio de los topónimos como nombres o etiquetas, sino en su análisis como signos o símbolos sociales en el marco de la Geografía. Los topónimos, como instrumentos geográficos para designar lugares lo suficientemente importantes en el imaginario colectivo (Woodman, 2012: 111), incorporan capas de significado más allá de las propias de las palabras originarias (Radding y Western, 2010) que permiten aprehender información sobre el territorio. Esta información puede consistir en, por ejemplo, el grado de relevancia que tiene un determinado lugar para un determinado colectivo (Lucas y Ordinas, 2013), que queda registrado en el conocimiento y la recurrencia de uso de su nombre, o el testimonio de una determinada política de gestión turística (Light, 2014), que queda reflejada en los topónimos que se señalizan en los cascos históricos de las ciudades, entre otras cuestiones.

En esta línea, se habla actualmente de un giro subjetivo en el análisis toponímico (RoseRedwood et al., 2010). Algunas corrientes emergentes, como las toponimias críticas (Berg y Vuolteenaho, 2009), promueven un nuevo entendimiento de la toponimia como elemento simbólico e incluso de poder territorial, capaz de interactuar con el paisaje e influir en él. En el análisis geográfico esto se traduce en estudiar los topónimos como elementos del territorio exclusivos e independientes, dotados de características únicas, combinando el análisis individual de cada nombre de lugar, necesariamente exhaustivo e indispensable para su comprensión (Martínez de Pisón, 2010: 25), y el análisis colectivo de los distintos topónimos, prestando atención a lo que significan y representan para cada individuo y cada colectivo. El estudio de los nombres de lugar sirve, en este escenario, de referencia y apoyo en el análisis crítico del territorio. En concreto, en los espacios urbanos, donde la impronta que dejan los ciudadanos sobre el territorio y sus topónimos es especialmente significativa, la comprensión de los nombres de lugar resulta de gran utilidad en el análisis integrado de la ciudad.

La toponimia constituye, en definitiva, una herramienta de información geográfica, cuyo aprovechamiento en el análisis urbano requiere de métodos que permitan reconocer y valorar los distintos significados e ideas que contiene. Las metodologías cualitativas tradicionales, aptas para la recopilación y el análisis de la toponimia, requieren una profunda revisión teórica y metodológica para que sea posible su utilización por las nuevas corrientes críticas de análisis geográfico de los topónimos.

\section{TÉCNICAS PARA EL ANÁLISIS DE LA TOPONIMIA URBANA}

En el estudio de la toponimia urbana se han empleado habitualmente métodos y técnicas propias de disciplinas como la Filología y la Lingüística aplicadas tanto en el análisis de cada topónimo de forma individual como en el estudio de los distintos conjuntos de topónimos. Sin embargo, como se indicaba, teniendo en cuenta la evolución de la ciencia toponímica se hace necesario plantear nuevos métodos y horizontes técnicos. Las toponimias críticas y otros enfoques actuales abogan por el estudio de la información que contienen los topónimos más allá de la puramente onomástica, lo que supone un enfoque metodológico distinto. Para trabajar con los topónimos es indispensable contar con herramientas que permitan comprenderlos desde su origen y en su contexto; es necesario conocer cómo se crean, cómo se usan y cómo evolucionan en la sociedad. Las herramientas y técnicas de análisis toponímico deben permitir la recopilación y el análisis de la información asociada al topónimo que no resulta inmediatamente perceptible a través de la mera lectura del nombre. 
En la vida cotidiana, los ciudadanos recopilan y utilizan la información toponímica que necesitan emplear para referirse al territorio al menos a partir de tres mecanismos diferenciados, ligados a su fuente de procedencia:

- Mecanismos interpersonales de información toponímica: a través de conversaciones o consideraciones propias, el ciudadano adquiere un bagaje toponímico social. En algunos casos, incluso, propone topónimos propios sin comprobar su veracidad social.

- Mecanismos de información toponímica explícita: el ciudadano recopila información toponímica de fuentes de información cuya función principal o exclusiva es la difusión de los nombres de los lugares, fundamentalmente cartelería, señalización y cartografía específicas.

- Mecanismos de información toponímica indirecta: el ciudadano también recibe indirectamente información toponímica a través de medios como la prensa, televisión u obras literarias que, con frecuencia, influyen de manera significativa en la manera en que el ciudadano recuerda y emplea los topónimos.

Atendiendo a esta heterogeneidad de mecanismos de recopilación y uso de la información toponímica, resulta evidente que el entendimiento completo de los topónimos requiere una profunda aproximación a los nombres en su ubicación y contexto. La investigación sobre el terreno constituye un requisito indispensable para poder recabar gran parte de la información que contienen los nombres de lugar, que solo se entiende en su totalidad dentro de su contexto espacial y con las percepciones de los ciudadanos. Para ello, es necesario disponer de técnicas que permitan conocer la información que contienen los topónimos según su procedencia y su funcionamiento en el imaginario colectivo. La combinación de técnicas de campo es la aproximación metodológica que se propone de cara a contemplar la heterogénea información que puede contener la toponimia. Para ilustrar esta propuesta metodológica se ha seleccionado la ciudad española de Toledo, como caso de estudio por la rica y variada toponimia que contiene y su diversidad cultural, histórica y social, que permite mostrar en detalle la capacidad que tienen los topónimos de suministrar información geográfica.

Las distintas técnicas propuestas (observación de campo, derivas urbanas, mapas mentales y encuestas) permiten recopilar gran cantidad de información sobre la ciudad que queda registrada en los nombres de lugar. La utilización de los distintos procedimientos y técnicas de campo, que se describen a continuación, resulta innovadora en el marco de las nuevas tendencias de análisis toponímico orientadas al análisis geográfico urbano.

\section{II.1. Aportaciones de la observación de campo al análisis de la toponimia urbana}

En el análisis toponímico moderno, la observación de campo, entendida como la visualización de la realidad de cada nombre de lugar sobre el terreno, constituye un requisito indispensable para la comprensión total de los topónimos. Visualizar el nombre in situ permite conocer y valorar una parte de la información metasemántica del topónimo ligada a la 
conexión del nombre con el lugar al que designa y que no es posible percibir de otro modo, como por ejemplo, la manera en que un topónimo se asimila en el imaginario individual o colectivo $^{1}$ o la veracidad del significado de un nombre en su propio medio ${ }^{2}$.

Las observaciones de campo en toponimia se plantean como observaciones analíticas centradas en recabar información sobre los aspectos más relevantes de la toponimia del lugar que se desea analizar: el tipo de señalización toponímica existente, la conexión del significado de cada nombre con la realidad del lugar, la percepción de sensaciones asociadas al nombre, el reconocimiento del valor del topónimo, etc. De este modo, la observación de campo permite detectar cuestiones sobre el contexto urbano que rodea al topónimo. Así, la observación de campo constituye una parte importante del análisis del significado de cada topónimo en su contexto específico.

La observación de campo como técnica toponímica se articula en torno a dos directrices fundamentales:

- La observación analítica de la información toponímica que existe físicamente en el paisaje: cartelería, señalización, esculturas, nombres de establecimientos comerciales, etc. Es de interés recoger y analizar cualquier texto escrito en el paisaje urbano. El observador debe preguntarse: ¿qué nombres se pueden leer?, ¿qué indica la forma y el lugar en que esos nombres se han rotulado?, ¿los nombres y/o la forma en que se presentan conectan con una idea concreta sobre los lugares a los que designan?

- El estudio sobre el terreno de los lugares a los que designan las referencias señalizadas en la cartelería, así como otras referencias previamente recogidas mediante otras técnicas. El observador debe cuestionarse: ¿qué conexión hay entre el significado del nombre y la realidad?, ¿qué información complementaria sobre el lugar que no se aprecia en el terreno proporciona el nombre?, si hay más de un nombre para designar un lugar, ¿cómo se materializa en la realidad este hecho?

La observación de campo también resulta especialmente apropiada para la identificación y el análisis de ectoponimia (Durán, 1998: 32), lugares que se reconocen en el espacio urbano, pero que carecen de topónimo para ser designados. Asimismo, facilita también detectar lugares que no existen o que han dejado de existir para nombres que aún perduran en las distintas fuentes.

1 Esto es, la forma en que un individuo reconoce un determinado topónimo en el paisaje, independientemente de que sea real o ficticio. El análisis de la toponimia de ficción también tiene un significativo interés geográfico (Arroyo, 2014), porque también se asimila en el imaginario colectivo.

2 Un ejemplo de esto sería Lo Blanco, un paraje toledano situado junto al barrio de Azucaica que, paradójicamente, consiste en un gran campo de color amarillo. La observación de campo de este topónimo ha permitido sugerir que el nombre tal vez proceda del nítido color blanquecino que da al suelo yesífero el sol de mediodía. El trabajo de campo resulta indispensable para entender el valor simbólico de esta referencia toponímica (y, en este caso, su transparencia). 


\section{II.2. Derivas urbanas como herramientas multidimensionales para el análisis de la toponimia urbana}

La deriva urbana es un paseo o itinerario por la ciudad de carácter espontáneo, sin un propósito definido (Martínez-Arrarás et al., 2013), motivado por el propio deseo de realizar el paseo. La propia espontaneidad o $\mathrm{azar}^{3}$ del itinerario constituye el comportamiento experimental de la acción y la define como un instrumento de recopilación y análisis de información geográfica en un sentido esencialmente subjetivo, puesto que permite recabar el imaginario reflexivo de la ciudad, esto es, las opiniones y valoraciones del paseante sobre el terreno, sin ser sometidas a ningún tipo de filtro ${ }^{4}$.

La deriva surge inicialmente como instrumento de creación artística al amparo de los movimientos dadaísta y surrealista. El dadaísmo, en los años 20, es el precursor de la exploración como técnica de lectura de los espacios urbanos con fines inicialmente artísticos (Cerdà, 2012). El surrealismo subsecuente, emplea la técnica de perderse en la ciudad para descubrir una realidad distinta, "marcada por el automatismo y la lectura de la ciudad inconsciente, o lo que es lo mismo, nuestra percepción onírica de la ciudad" (Cerdà, ibíd.). Pasear la ciudad permite dialogar con ella, entender lo que muestra y narra en sus calles y paisajes.

La conceptualización de las derivas o itinerarios urbanos como práctica metodológica surge a partir del situacionismo (Debord, 1958). La palabra deriva significa para los situacionistas iniciar una caminata sin objetivo específico, usualmente en una ciudad, que sigue la llamada del momento. El filósofo francés Guy Debord propone utilizar las derivas para reflexionar sobre las formas de visualizar y experimentar la vida urbana en el marco de la psicogeografía ${ }^{5}$. Los situacionistas, que se niegan a ser considerados artistas, desarrollan la deriva como acción experimental ${ }^{6}$ para el entendimiento de la ciudad.

En la deriva, "el paseante se torna poroso pero activo, reflectante, donde todo lo que observa tiene una proyección creativa sobre el mundo" (López, 2014), permitiendo la construcción de una secuencia narrativa sobre la ciudad. Generalmente, dicha narración se materializa en una memoria de itinerario, cuyo análisis permite aproximarse a la ciudad a partir de las percepciones libres de sus usuarios. En el caso de la toponimia, las memorias de las derivas conforman relatos de la experiencia urbana donde los topónimos constituyen la conexión entre la narración y el lugar. Tiene, entonces, una importancia capital qué nombres se utilizan o se omiten en los textos elaborados a partir de las derivas urbanas, así como la manera en que se utilizan y la impronta que dejan sobre el discurso elaborado. En las memorias de las

3 Cabría matizar la idea de azar en este contexto, puesto que el carácter aleatorio de la deriva, queda inevitablemente parcializado por una serie de condicionantes físicos y psicológicos con frecuencia difícilmente identificables.

4 "La característica principal de la deriva es que no se acota el campo de observación. Sólo se escoge el entorno urbano objeto de estudio, por el cual se va a derivar. Durante la caminada se recogen los datos, a modo de texto/discurso. La trayectoria/relato permite al investigador reconocer e interpretar los aspectos urbanos y sociales. Así pues, mediante la deriva y gracias al movimiento, al deambular, al traslado, se recopila información sobre la ciudad, que posteriormente será analizada." (Pellicer et al., 2013: 130).

5 El estudio de los efectos precisos del medio geográfico (consciente o no) que actúa directamente sobre el comportamiento afectivo de los individuos (Cerdà, 2012).

6 Guy Debord (1958) conceptualiza esta técnica como "una técnica de paso ininterrumpido a través de ambientes diversos". 
derivas, incluir un topónimo es similar a visitar un determinado lugar durante el itinerario, supone ponerlo en escena, valorarlo (Méndez, 2012). Analizar la toponimia de las memorias permite conocer cómo se percibe cada lugar y qué importancia y significado tiene para cada paseante.

Dada la función que cumple el nombre geográfico en las memorias de los itinerarios urbanos, éstas constituyen instrumentos idóneos para el estudio y el análisis de la toponimia urbana a tres niveles:

- Proporcionan información complementaria para el análisis metasemántico del topónimo: las memorias de los itinerarios constituyen una aproximación al funcionamiento del topónimo en el inconsciente colectivo ${ }^{7}$.

- Ponen de relieve implicaciones artístico-patrimoniales de los nombres: las derivas permiten incorporar la perspectiva artística a la lectura del valor del nombre en la ciudad, ya que presentan a cada nombre en su contexto de uso y percepción. El topónimo se presenta a menudo como un objeto artístico que sugiere, evoca, emociona, etc.

- Constituyen herramientas de validación de la credibilidad de la investigación en toponimia: durante la ejecución de las derivas, el informante ejerce juicios de valor sobre los nombres de lugar, por lo que las memorias pueden servir para validar ideas específicas sobre topónimos concretos en base al imaginario colectivo.

\section{II.3. Mapas mentales como instrumentos para la recopilación, valoración y análisis de la topo- nimia urbana}

Los mapas mentales son esquemas de percepción individual del espacio elaborados por un informante de forma libre o dirigida por una serie de premisas o una encuesta. Proporcionan información geográfica acerca de la relación que establece el ciudadano con la realidad del lugar representado, por lo que su utilidad resulta evidente y su uso está generalizado en diversas disciplinas. Comienzan a extenderse como técnica de análisis con la geografía de la percepción (Pillet, 2004) como un instrumento conciliador entre las orientaciones positivistas y humanistas, capaz de plantear un resultado material propio de ciencias como la Psicología, pero incorporando la dimensión de la representación, propia de los humanistas.

Según el tipo de uso que se hace de los mapas mentales, pueden funcionar como mapas de percepción del espacio, mapas de interpretación del espacio o croquis mentales de lo que un ciudadano es capaz de recordar sobre un determinado espacio (Didelon et al., 2011). En los tres casos, los mapas mentales se emplean como herramientas de recolección de información sobre la forma en que los encuestados entienden y perciben los lugares y cualquier elemento del territorio que se desee analizar específicamente ${ }^{8}$. Kevin Lynch (1960), en el

7 En el sentido de representaciones comunes al género humano. Los topónimos, en las derivas, no son el elemento protagonista (que es la ciudad), pero si la referencia a través de la cual el conjunto de los ciudadanos expresan sus ideas de los lugares.

8 Los mapas mentales se presentan como "instrumentos para entender cómo los distintos individuos perciben su entorno, entendiendo dicho ejercicio como una aproximación al conocimiento de los modelos espaciales mentales" del lugar (Lucas y Ordinas, 2013). 
marco del behaviourismo americano, sienta las premisas elementales de los distintos objetos que se pueden identificar en los mapas mentales: sendas, nodos, hitos, barrios, distritos, bordes y mojones. Entre otras cuestiones, el análisis de estos elementos permite determinar, a nivel general, cuáles son los espacios simbólicos de un determinado lugar ${ }^{9}$ (los que son representativos para un colectivo amplio a cualquier nivel).

Como técnica toponímica, los mapas mentales facilitan entender cómo un determinado informante percibe o responde frente a un determinado nombre geográfico, en un lugar concreto, a partir de la información toponímica que incluye en su croquis y la forma en que la rotula. Los nombres incorporados u obviados en cada croquis, ya sea de forma intencional o casual, reflejan la relación de cada encuestado con ese lugar y/o su nombre. Los mapas mentales en toponimia funcionan, entonces, como representación gráfica de las ideas y percepciones sobre los nombres y los lugares por parte de los ciudadanos. En definitiva, como instrumento de análisis toponímico, se materializan como mapas interpretativos.

\section{II.4. Encuestas orientadas al análisis toponímico}

La encuesta constituye la técnica de recopilación y análisis de información toponímica más tradicional. Existen multitud de experiencias con encuestas estructuradas y no estructuradas en trabajos recientes de Geografía y Toponomástica (García et al., 2002; Membrado, 2012). Las encuestas han constituido, además, la fuente clásica de referencia para la recopilación de denominaciones. La Organización de Naciones Unidas, en su Manual para la Normalización Nacional de Nombres Geográficos (Kerfoot, 2006), considera la encuesta como el método ideal para obtener información sobre el uso local de los nombres geográficos y sus aplicaciones, refiriéndola como el único medio para obtener algunos tipos de información toponímica, en particular la basada en datos lingüísticos.

Recientemente, las encuestas han visto potenciado su valor como herramienta directa e indirecta de análisis toponímico por la emergencia de las toponimias críticas. En el estudio de los nombres como símbolos, las encuestas permiten interrogar a los ciudadanos sobre todo lo que rodea al topónimo y sobre su funcionamiento y su comportamiento en el imaginario colectivo. Algunas preguntas que se hacen hoy día los investigadores en materia de toponimia son (Ainiala y Vuolteenaho, 2011: 3): ¿de qué forma se relacionan los nombres con la construcción de estructuras de poder o de identidades sociales? o ¿cuál es el papel de los topónimos en la vida cotidiana y en la percepción del espacio urbano?

En este escenario, la encuesta constituye una herramienta de análisis del contexto de cada nombre y de lo que cada nombre implica. Así, en las encuestas en materia de toponimia las preguntas no solo se destinan a conocer qué nombres de lugar utiliza el encuestado, sino también cómo los usa y cómo interactúa con ellos. Por tanto, es de interés preguntar, por un lado, por lo que evoca y sugiere un topónimo, lo que permite abordar el análisis de cuestiones como la identidad local y la percepción del espacio urbano (por ejemplo, se puede preguntar

9 Yi-Fu Tuan (1974) diferencia entre topofilia (referido a los lugares con los que los ciudadanos mantienen lazos sólidos y afectivos); topofobia (lugares que provocan rechazo); topolatría (lugares míticos o con carácter reverencial), toponegligencia (lugares indiferentes para el ciudadano), etc. 
al encuestado lo que le sugiere un nombre concreto o si hay algún nombre que le provoque atracción o rechazo). Por otro lado, es también de interés preguntar por los mecanismos de difusión y transmisión del topónimo, cuyo análisis facilita abordar el significado cotidiano de los nombres y las estructuras mentales que se generan en torno a ellos (se puede preguntar al encuestado cuestiones en relación con recuerdos asociados a la primera vez que leyó un determinado topónimo o a posibles ideas preconcebidas que tenga sobre un lugar porque las asocie a un nombre específico).

\section{APLICACIÓN DE TÉCNICAS TOPONÍMICAS EN TOLEDO}

El análisis de distintos topónimos toledanos (fig. 1) a partir de observaciones de campo, derivas urbanas, mapas mentales y encuestas, ha permitido detectar información sobre la ciudad que no resulta inmediatamente perceptible con la mera lectura de cada nombre. Se muestran, a continuación, una serie de ejemplos del trabajo efectuado escogidos selectivamente.

Figura 1

\section{LOCALIZACIÓN DE LOS TOPÓNIMOS YLUGARES}

TOLEDANOS SELECCIONADOS

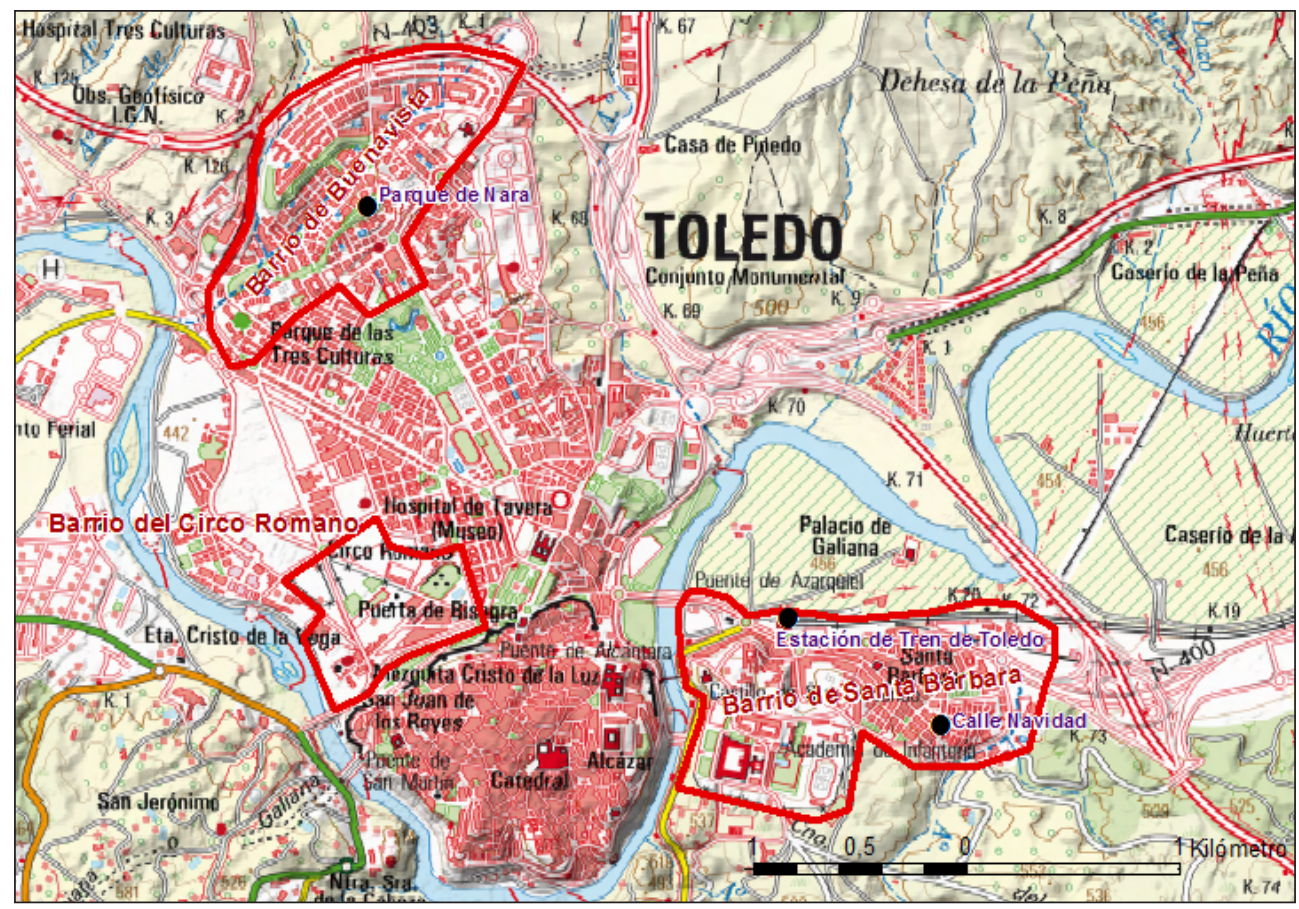

Los topónimos seleccionados para ilustrar el trabajo efectuado son el Barrio del Circo Romano; la Estación de Tren de Toledo y la Calle Navidad, en el barrio de Santa Bárbara; y el Parque de Nara, en el barrio de Buenavista. Elaboración propia sobre cartografía del Mapa Topográfico Nacional. 


\section{III.1. Observación de campo en el barrio del Circo Romano}

El barrio del Circo Romano, en el margen norte de la muralla del casco histórico de Toledo, constituye un lugar donde la observación de campo resulta especialmente interesante en el estudio de la toponimia local. Los nombres del barrio permiten conocer determinados aspectos del lugar irreconocibles de otro modo.

La toponimia del Circo Romano resulta tan heterogénea como el paisaje que lo caracteriza. Por todo el barrio se puede constatar la existencia de una cartelería muy variada con topónimos muy diversos y referencias muy heterogéneas a distintos momentos históricos de la ciudad: Carlos III (monarca Borbón), Mas del Ribero (coronel franquista), el propio Circo Romano (referencia a la época de dominación romana), etc. Este hecho constituye una prueba de la larga y compleja historia del barrio. En general, los nombres se encuentran mal documentados y la señalización resulta muy deficiente por todo el entorno. En la mayoría de los casos, la cartelería no tiene una función turística sino meramente indicativa, a pesar de los numerosos lugares de interés turístico que alberga el barrio (fig. 2 y 3 ).
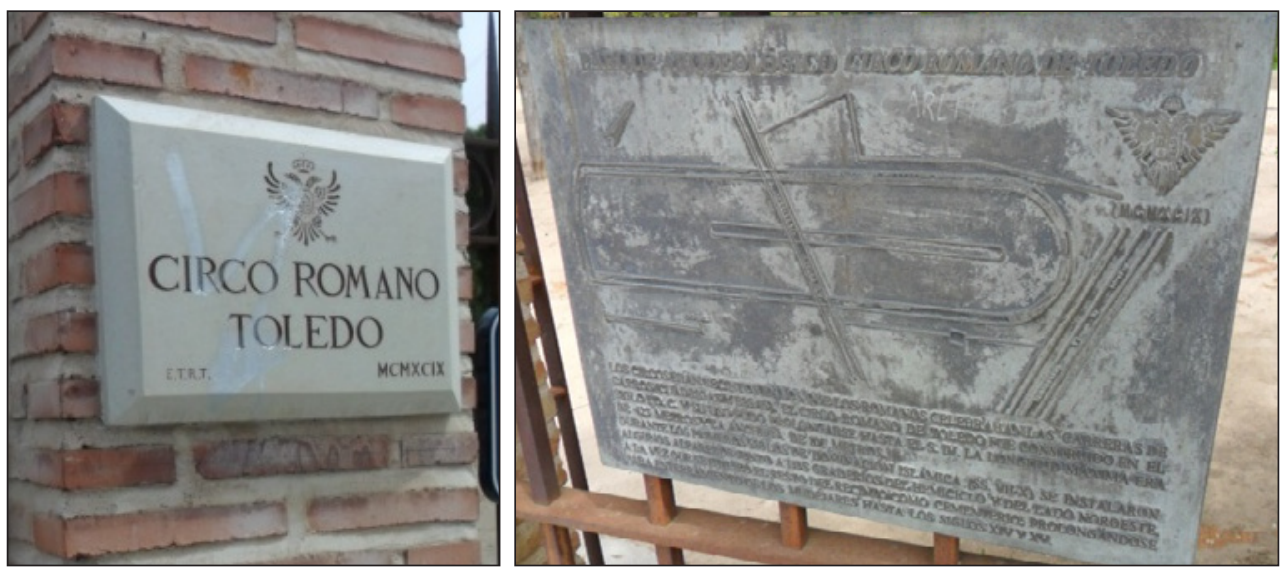

Hasta la intervención del Ayuntamiento de Toledo con la remodelación del eje principal del barrio, el Paseo del Circo Romano (2012-2013), estos carteles, en el parque urbano Campo Escolar, eran los únicos que proporcionaban información turística sobre el lugar (en este caso, únicamente sobre el circo romano) que, como se puede apreciar, resultan muy discretos y recogen poca información. Fotografías del autor.

Las vías urbanas del barrio del Circo Romano contienen, en su mayor parte, referencias a elementos religiosos, aunque no de forma exclusiva. Topónimos como Paseo de Canónigos o Travesía del Cristo de la Vega ponen de relieve la tradición cristiana del lugar. Sin embargo, el carácter religioso del barrio parece haberse difuminado en tiempos recientes, tal y como se puede apreciar en algunos elementos toponímicos. Por ejemplo, el cartel que señaliza el acceso al Cristo de la Vega, un monumento histórico del 
barrio de cierto interés turístico, llama la atención por su diseño obsoleto, que sugiere una cierta pérdida de protagonismo de este lugar en el conjunto de la ciudad (fig. 4).

Por otra parte, los nombres de lugar del barrio del Circo Romano se evidencian como parte de su acervo territorial. En general, son nombres cargados de significado histórico y cultural y, por ello, no es de extrañar que existan algunos carteles que pongan en valor determinados lugares y nombres del barrio (fig. 5).
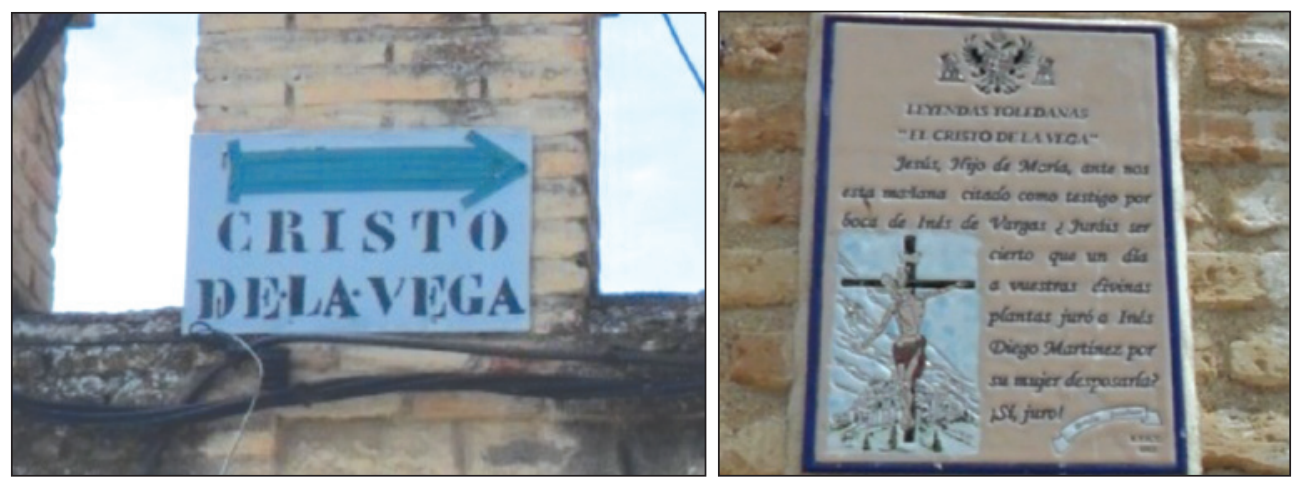

Izquierda: el cartel que anuncia la ubicación del Cristo de la Vega resulta muy antiguo y rudimentario en comparación con el resto de la cartelería del barrio y de la ciudad. Derecha: en el interior del recinto del Cristo de la Vega, la conocida leyenda del Cristo de la Vega, narrada por José Zorrilla en su obra A buen juez, mejor testigo, aparece rotulada en la cartelería, poniendo en valor la importancia del lugar y su topónimo. El texto se corresponde con uno de los pasajes más conocidos de la leyenda. Fotografías del autor.

En el barrio del Circo Romano existen importantes deficiencias en la señalización de algunos lugares. Un ejemplo lo ofrece la propia avenida principal del barrio, el Paseo del Circo Romano, que carece de una placa en la que figure su nombre en todo su trazado. Esta simbólica situación es paradigmática del estado de abandono de este barrio, especialmente en lo referido a la puesta en valor de sus numerosos restos arqueológicos. Los topónimos más recientes sí se encuentran bien documentados y es reseñable el esmero puesto en la rotulación de algunos nombres de vías urbanas (fig. 6).

Como elemento idiosincrático de la toponimia del barrio del Circo Romano, la observación de campo permite constatar la significativa presencia, por todo el barrio, de numerosos topónimos particulares imbricados de un simbolismo muy revelador. Por un lado, existen varias denominaciones históricas que no se han modificado en absoluto, como la histórica Venta de Aires, cuyo nombre evoca las tradicionales ventas del siglo XIX, aunque en la actualidad sea únicamente un restaurante. Por otro lado, la toponimia de los establecimientos comerciales más recientes utiliza términos propios del contexto histórico y turístico de la ciudad, como el Restaurante la Almazara, que remite a un inexistente molino de aceite; Damasquinados Suárez, que remite a la artesanía toledana tradicional, buscando poner de relieve la condición turística del barrio; o los Apartamentos Circo Romano (fig. 7), que remite al circo como reclamo turístico. 
En el caso del barrio del Circo Romano, queda patente el valor de la observación de campo como técnica de análisis toponímico, que permite reconocer sobre el terreno cierta información geográfica que contienen los topónimos del barrio que facilita entender mejor su origen y su contexto histórico y actual.

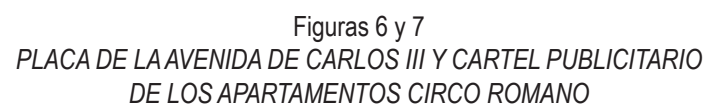

Figuras 6 y 7

PLACA DE LAAVENIDA DE CARLOS III Y CARTEL PUBLICITARIO

DE LOS APARTAMENTOS CIRCO ROMANO
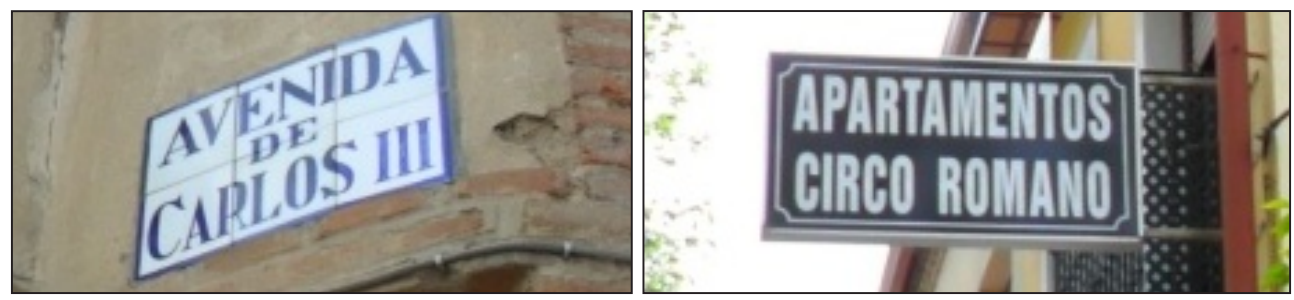

Izquierda: la cerámica con la que se señalizan algunos topónimos del barrio se parece significativamente a la que se emplea en el casco histórico de la ciudad. Derecha: en el caso de los Apartamentos del Circo Romano, la referencia al Circo Romano se ha utilizado como elemento publicitario. Fotografías del autor.

\section{III.2. Las derivas urbanas en la lectura de los lugares del barrio de Santa Bárbara}

Para el análisis de la toponimia toledana a través de las derivas urbanas, se ha solicitado a una serie de informantes ${ }^{10}$ que elaboren una memoria de su experiencia en un itinerario libre por distintos barrios de la ciudad, prestando atención específica a determinados aspectos relacionados con la toponimia durante su paseo.

Para la explotación de las memorias, se ha establecido como pauta metodológica de análisis la consideración de la ciudad como un elemento textual y metafórico (Barnes y Duncan, 1992; Beuchot y Coca, 2013). En este contexto, se plantea que la ciudad es similar a un texto donde los signos, como en este caso, los topónimos, constituyen elementos referenciales en torno a los que se articula el discurso sobre el espacio urbano. Los relatos de las derivas se plantean, entonces, como discursos territoriales donde los topónimos tienen un significado personal, cuya interpretación permite recabar la información que transporta y transmite cada nombre.

El abordaje analítico de las memorias de las derivas se ha efectuado a partir de una serie de lecturas reiteradas de cada texto, primero generales, y después con el objetivo de interpretar el contenido de cada topónimo de forma individual, comparando los distintos testimonios. Se muestran a continuación dos ejemplos del trabajo realizado con topónimos concretos de Toledo:

10 Estudiantes del grado de Geografía y Ordenación del Territorio. Se ha considerado de interés emplear informadores sensibilizados o conocedores de la morfología urbana y familiarizados con el trabajo de campo en Geografía con el objetivo de que durante la deriva tengan en cuenta el papel que juegan los topónimos en la ciudad, que para otro tipo de profesionales constituyen simples etiquetas cartográficas. 
- Estación de Tren de Toledo. La estación de ferrocarril de la ciudad se localiza en el barrio periférico de Santa Bárbara (al este del Tajo y del Casco Histórico), que conforma uno de los arrabales más antiguos de la ciudad. En las memorias, el topónimo de la Estación se ha evidenciado como el elemento fundamental de referencia en el barrio para los vecinos. El análisis de los discursos de los informantes ha permitido poner de relieve que el Tren de Alta Velocidad, que llega a la Estación, dota de un protagonismo especial al barrio de Santa Bárbara en el conjunto de la ciudad. En Toledo, la estación tiene un importante valor como hito referencial y como símbolo del barrio, incluso para los que no son usuarios del servicio ferroviario. Distintas aseveraciones de los testimonios analizados así lo atestiguan (tabla 1$)$.

Tabla 1

SELECCIÓN DE TESTIMONIOS DE INFORMANTES EN RELACIÓN CON LA ESTACIÓN DE TREN

“(...) la Huerta del Rey (...) es invisible para muchas personas. (...) Está fuera del entorno urbano, el
AVE le quita todo el protagonismo, no hay indicativos.” INFORMANTE 1

Los testimonios de los informantes, totalmente independientes en el marco de las derivas urbanas, ponen de manifiesto el papel referencial que se le otorga a la Estación en el barrio de Santa Bárbara. Este hecho queda patente en que, por ejemplo, la vecina Huerta del Rey, paraje histórico que alberga el conocido Palacio de Galiana, pasa desapercibida por la existencia de una estación "elegante", "accesible" y "referencial". Elaboración propia a partir de ejercicio experimental con derivas urbanas, noviembre de 2013.

La deconstrucción del discurso y la contrastación de opiniones, comparando los aspectos más relevantes señalados por los informantes, deja patente el interés de las derivas como herramienta de extracción de conocimiento sobre los lugares a través de sus nombres.

- Calle Navidad. El topónimo Calle Navidad, en la zona residencial de Santa Bárbara, constituye una denominación fuera del patrón propio de los nombres de las calles del barrio, donde predomina la toponimia mariana y, pese a la referencia religiosa del término Navidad, resulta un nombre de lugar llamativo. El carácter diferenciador de este topónimo permite plantear algunas ideas concretas que quedan asociadas a él en los discursos de los informantes (tabla 2). En este caso, el análisis comparativo de las ideas que recoge cada memoria facilita el análisis interpretativo del nombre, proporcionando información sobre el lugar al que designa. 


\begin{tabular}{|c|c|}
\hline $\begin{array}{l}\text { Consideraciones efectuadas por los informantes al } \\
\text { transitar por la Calle Navidad }\end{array}$ & Observaciones \\
\hline $\begin{array}{l}\text { INFORMANTE } 1 \\
\text { "(...) Edificios donde vivir de esos con colores naranjas y } \\
\text { grises. (...) La verdad es que el lugar es deprimente (...) Y } \\
\text { con el aburrido y monótono gris se potencia, ¡cómo no! el } \\
\text { carácter del toledano.” }\end{array}$ & \multirow{3}{*}{$\begin{array}{l}\text { - La etiqueta Calle Navidad activa } \\
\text { una serie de ideas muy concretas } \\
\text { sobre el paisaje físico y cultural } \\
\text { del lugar al que designa. Se trata } \\
\text { de un topónimo fácil de reconocer } \\
\text { (resulta, además, muy diferente a los } \\
\text { topónimos propios del barrio, por lo } \\
\text { que es fácilmente identificable) que } \\
\text { se relaciona con una tipología de } \\
\text { edificaciones y unas características } \\
\text { muy concretas ("gris", "tranquilo", } \\
\text { "vivienda antigua", etc.), que } \\
\text { sirven de referencia general para la } \\
\text { descripción del barrio. } \\
\text { - Este nombre es historia obrera } \\
\text { del barrio y constituye un claro } \\
\text { testimonio de la génesis del barrio, } \\
\text { no solo a nivel paisajístico, sino } \\
\text { también toponímico. La referencia } \\
\text { Navidad se corresponde con el } \\
\text { hecho de que se trata de viviendas } \\
\text { proporcionadas a vecinos con } \\
\text { escasos medios económicos durante } \\
\text { la navidad de 1953, por lo que el } \\
\text { topónimo es la reminiscencia de una } \\
\text { actuación urbana y se asocia a un } \\
\text { colectivo social muy específico. }\end{array}$} \\
\hline $\begin{array}{l}\text { INFORMANTE } 4 \\
\text { "Durante la deriva uno se puede dar cuenta de que no es un } \\
\text { barrio rico, y que dentro hay diferentes zonas desde las zonas } \\
\text { que dan al Paseo de la Rosa, principal avenida y frontera del } \\
\text { barrio (...) hasta otras zonas como la de la Calle Navidad, } \\
\text { que a simple se ve su historia obrera y su poco poder } \\
\text { adquisitivo. (...) } \\
\text { Es una zona más de vivienda más antigua que el resto del } \\
\text { barrio, que parece una zona obrera. Las calles son estrechas } \\
\text { y con un plano regular de la zona. (...) con este tipo de } \\
\text { viviendas, muchas deshabitadas, y otras habitadas parece } \\
\text { con familias con pocos recursos o de tradición obrera asentada } \\
\text { allí. (...) la mayoría conocía esta pequeña zona, (...) puede } \\
\text { ser un elemento importante para poder ver lo que ha sido el } \\
\text { barrio de Santa Bárbara y su evolución urbana y social.". }\end{array}$ & \\
\hline $\begin{array}{l}\text { INFORMANTE } 7 \\
\text { "(...) un barrio muy tranquilo. Lo que me llama más atención } \\
\text { son las casas abandonadas. (...) ¿Por qué no hacen nada con } \\
\text { las casas abandonadas, ni las derrumban ni las rehabilitan? } \\
\text { También en esta zona existe un fenómeno muy interesante: las } \\
\text { casas modernas y las casas antiguas se encuentran mezcladas.” }\end{array}$ & \\
\hline
\end{tabular}

Elaboración propia a partir de ejercicio experimental con derivas urbanas, noviembre de 2013.

Tal y como muestran los ejemplos, las derivas proporcionan información sobre los topónimos a través de las percepciones de los informantes, que utilizan los nombres como referencia para las explicaciones de sus ideas sobre el lugar ${ }^{11}$. A diferencia de las observaciones de campo, no están estructuradas de una forma sistemática ni están diseñadas exclusivamente para la investigación toponímica, pero proporcionan una cantidad extraordinaria de información sobre los nombres de lugar.

11 Cabe suponer que en caso de haber escogido otro tipo de informantes no familiarizados con la información geográfica y la toponimia, la utilidad de las derivas como técnica toponímica de análisis urbano no habría resultado tan sumamente evidente. No obstante, toda memoria de un itinerario siempre va a requerir de la existencia de topónimos (de forma explícita o, al menos indirectamente) que se asocien a una idea sobre el lugar. 


\section{III.3. Los mapas mentales para el análisis de la toponimia del barrio de Buenavista}

De cara recopilar la información toponímica que se puede recabar a través de los mapas mentales, para el caso de Toledo se ha propuesto a una serie de encuestados que elaboren un croquis de su barrio incluyendo y nombrando, sobre su propio mapa, sus límites físicos y los lugares que consideran más representativos. Posteriormente, se les ha indicado que señalen qué elementos concretos de su barrio tienen mayor relevancia para ellos y cómo los denominan. Finalmente, se han efectuado distintas preguntas destinadas a complementar la información toponímica del mapa, interrogando sobre aspectos concretos (denominaciones de los principales accesos al barrio, topónimos que suscitan una determinada emoción al encuestado, etc.). Según la información explicitada por cada encuestado, se han podido definir distintos niveles de interés de los mapas, fundamentalmente en función de la riqueza informativa (el número de topónimos introducidos) y la calidad y la exactitud posicional de cada denominación rotulada.

El análisis de la información toponímica de los croquis se ha llevado a cabo a tres niveles:

- Se ha efectuado un análisis de contenido interpretativo de cada mapa de forma individual y otro comparativo contrastando los distintos mapas a través de preguntas de referencia para identificar características generales y específicas de los nombres y, por extensión, de los lugares a los que designan: ¿qué nombres de lugar se han incluido de forma recurrente?, la forma en que se ha rotulado cada topónimo ¿sugiere algo?, ¿las referencias incluidas son principales o secundarias?, ¿los nombres que se han incluido son oficiales, variantes o incorrectos? Se han detectado, de este modo, características generales de la toponimia de los distintos barrios analizados e ideas específicas sobre topónimos concretos que proporcionan información sobre el imaginario toponímico del barrio.

- Se ha efectuado una aproximación al conjunto de la información toponímica recogida a través de la visualización cartográfica de los nombres recopilados. Para ello, se ha representado toda la toponimia recogida en los mapas mentales de los informantes sobre una base cartográfica real, de cara a valorar el peso específico de cada nombre de lugar en el imaginario colectivo y determinadas características del barrio relacionadas con la información que proporciona la toponimia que solo resultan perceptibles en un formato cartográfico.

- Se ha efectuado una revisión comparada del tratamiento de topónimos concretos en los distintos mapas mentales. Los croquis han permitido poner de relieve la existencia de nombres autóctonos o de determinados comportamientos de los informantes respecto a nombres y lugares concretos, como la creación colectiva de topónimos para lugares que carecen de nombres oficiales.

En términos generales, el estudio de la toponimia de los mapas mentales permite profundizar en el conocimiento de las características del barrio y su población. A modo de ejemplo, los croquis que se muestran a continuación, recopilados en el barrio toledano de Buenavista, en el ensanche norte de la Toledo, revelan la prevalencia de la toponimia privada -fundamentalmente comercios y locales de restauración de uso cotidiano- en la configuración del imaginario individual de un barrio de nueva urbanización respecto a otros barrios más consolidados (fig. 8 y 9 ). 
Figuras 8 y 9

MAPAS MENTALES ELABORADOS POR ENCUESTADOS EN EL BARRIO DE BUENAVISTA
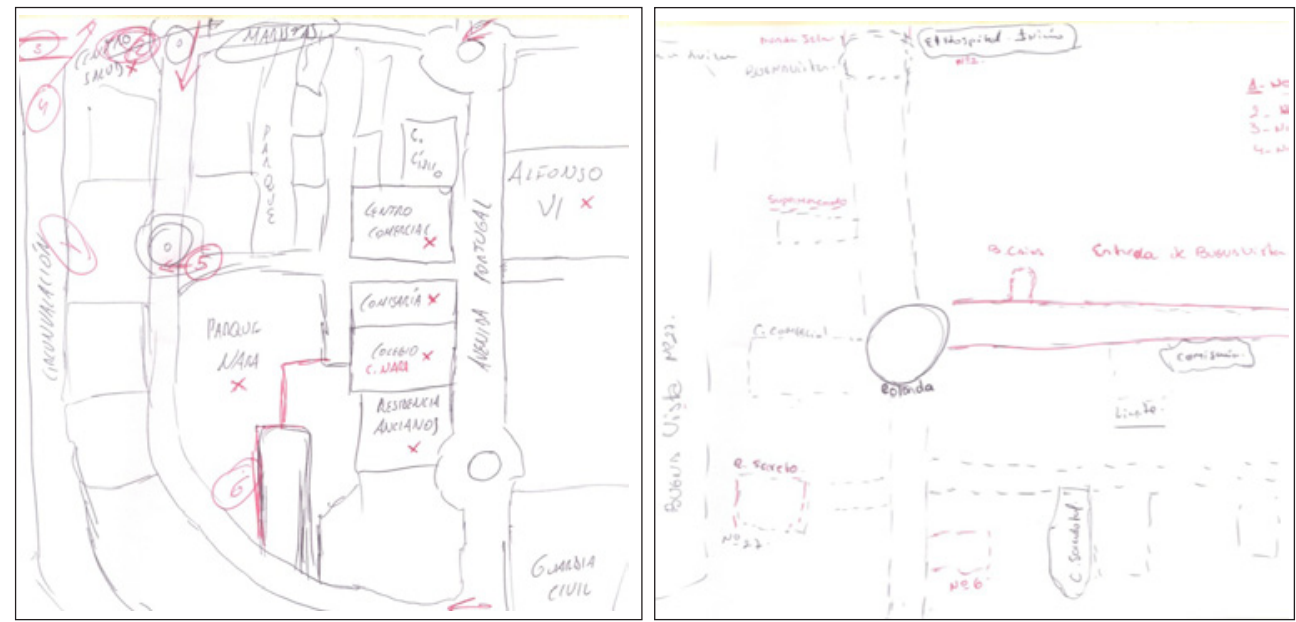

En los croquis recopilados en el barrio de Buenavista, predomina la toponimia privada y los términos genéricos aislados, que son testimonio de la falta de consolidación del barrio. En otros barrios de la ciudad, la recurrente rotulación de topónimos de zonas del barrio, plazas o nodos contrasta con la excesiva presencia, en este caso, de referencias genéricas como Rotonda o Centro comercial. Fuente: encuestas de campo, noviembre de 2012.

Por otro lado, en Buenavista, el análisis de la toponimia de los mapas mentales ilustra la importancia de las principales calles y avenidas del barrio como referencia en el imaginario colectivo por encima de plazas, edificaciones y otros hitos y lugares. En este barrio, los nombres de vías de comunicación tienen una importancia capital como principales identificadores geográficos de los vecinos ${ }^{12}$. El predominio de las morfologías urbanas privatizadas que reducen el espacio público dota de una gran importancia referencial a las vías urbanas entre megamanzanas cerradas. Esta cuestión es fiel reflejo de cómo las nuevas tendencias urbanas de encierro físico-social (Rodríguez, 2006) cambian el entendimiento de la toponimia y viceversa: los ciudadanos incorporan en sus mapas mentales solo la toponimia que conocen, que resulta escasa al tratarse de un barrio de manzana cerrada, del mismo modo en que la gran cantidad de suelo privado en el barrio hace difícil que los vecinos puedan conocer más topónimos de su barrio.

Por último, para el caso de Buenavista, resulta también de interés el análisis conjunto de los topónimos rotulados con mayor frecuencia en los distintos croquis mentales del barrio (fig. 10). La recurrencia de determinados topónimos en el imaginario colectivo permite profundizar en el conocimiento del lugar. En este caso, por ejemplo, se puede constatar que los principales lugares de tránsito y referencia para los vecinos del barrio son la Ronda de Buenavista y las avenidas que conectan el barrio con la ciudad histórica (Avenida

12 Este hecho también confirma que se trata de un barrio en proceso de consolidación, porque aún no se han generado espacios centrales de referencia para los vecinos y los nombres de las grandes vías urbanas son la principal referencia toponímica de la que pueden echar mano los encuestados a la hora de dibujar y nombrar los lugares más importantes de su barrio. 
de Europa, Avenida de Portugal, Avenida de Francia). También, se puede constatar la significativa difusión de una denominación autóctona no oficial como es Plaza de España ${ }^{13}$.

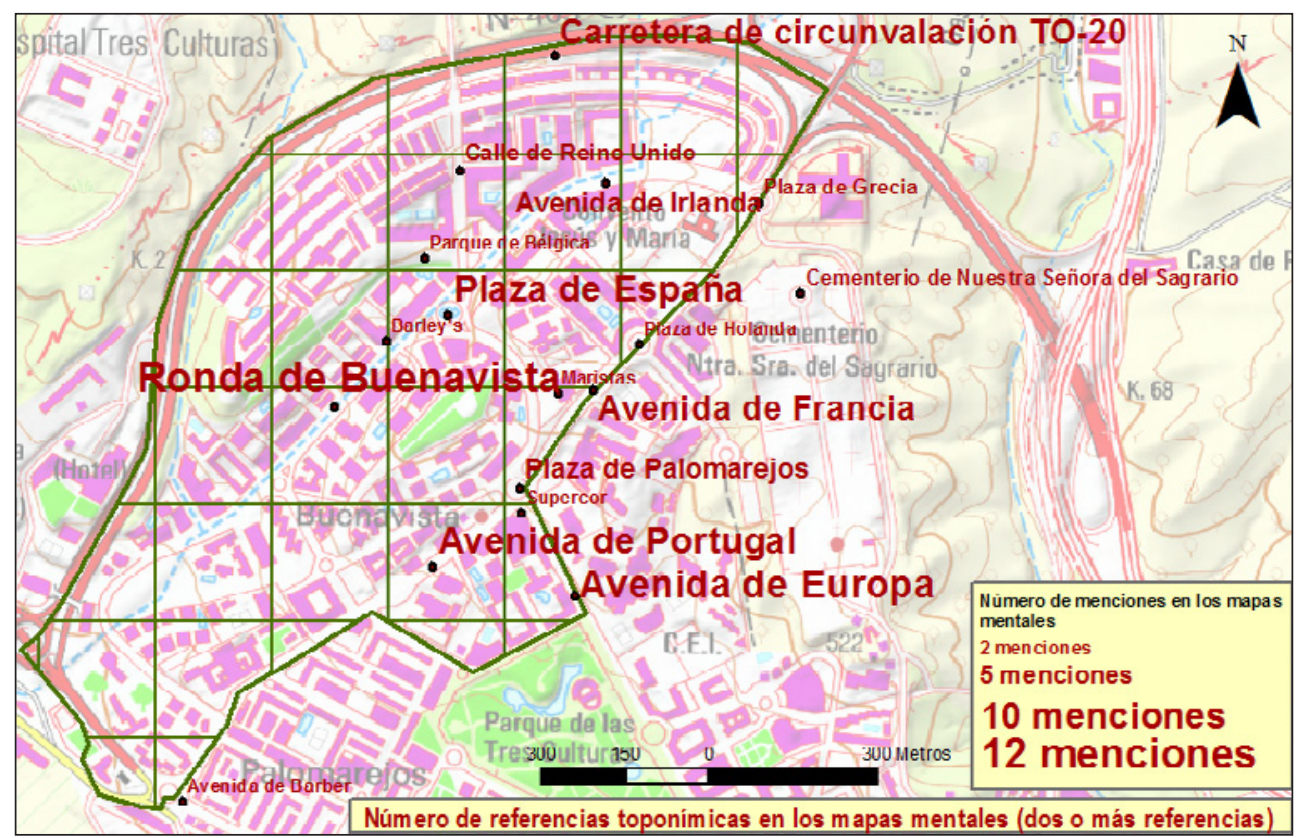

Principales referencias rotuladas en los mapas de los encuestados en el ámbito estudiado sobre un total de 29 mapas mentales con toponimia. Tamaño de letra proporcional al número de menciones (progresivamente de 2 a 12). Solo se rotulan como referencia en la leyenda los valores extremos y dos casos de valores intermedios (5 y 10). Elaboración propia a partir de encuestas de campo, noviembre de 2012.

\section{III.4. La encuesta como técnica toponímica para profundizar en el conocimiento de lugares toledanos}

En las encuestas diseñadas para el análisis toponímico de Toledo, se ha planteado una serie de preguntas sobre toponimia que ponen de relieve el tipo de información geográfica que puede extraerse cuestionando a los ciudadanos sobre aspectos concretos de los nombres de lugar. A modo de ejemplo, se muestran a continuación algunas de las preguntas efectuadas junto a una serie de reflexiones acerca de la información sobre el barrio que el análisis toponímico de las distintas respuestas permite extraer:

13 Plaza de España es una denominación acuñada por los propios vecinos para referirse a una glorieta situada en el centro de Buenavista que, tal y como se constata con su recurrencia en los mapas mentales, se encuentra bastante consolidada en el imaginario colectivo. 
- ¿Considera que su barrio está bien señalizado? Esta pregunta tiene una importancia capital en el entendimiento de la toponimia urbana, ya que la relación más inmediata del ciudadano con su toponimia es a través de la señalización. La manera en que la información toponímica aparece reflejada en la señalización se relaciona directamente con el grado de orientación del encuestado y su capacidad de identificar las distintas referencias toponímicas sobre el territorio. Las distintas respuestas recibidas han permitido conocer, por ejemplo, los problemas de familiarización con el territorio que genera una deficiente señalización toponímica (tabla 3).

Tabla 3

SELECCIÓN DE RESPUESTAS RECOGIDAS A LA PREGUNTA ¿CONSIDERA QUE SU BARRIO ESTÁ BIEN SEÑALIZADO?

"Echo en falta señalización de accesos, lugares de interés y transportes públicos." (encuestado en el barrio de San Antón, al sureste de Buenavista)

"Echo en falta información sobre lugares de interés para el barrio, como por ejemplo la asociación de vecinos" (encuestado en el barrio de San Antón)

"El barrio no está bien diferenciado con el resto de barrios del norte de Toledo, es difícil delimitarlo." (encuestado en el barrio de Buenavista)

"Se podría señalizar el parque de Tres Culturas." (encuestado en el barrio de Buenavista)

Elaboración propia a partir de encuestas de campo, noviembre de 2012.

- ¿Qué le sugiere este topónimo? Los nombres constituyen símbolos en torno a los cuales se articulan opiniones sobre los lugares, recuerdos, opiniones, etc. Preguntar a los encuestados por lo que activa cada topónimo en su imaginario personal permite conocer en profundidad lo que implica cada nombre en su contexto y lo que significa para el conjunto de los ciudadanos. En el ejemplo seleccionado (tabla 4) se pueden constatar las distintas capacidades de los nombres en el barrio de Santa Bárbara. El nombre Estación de Toledo, por ejemplo, estimula fundamentalmente juicios de valor sobre el lugar, mientras que otras referencias, como Academia de Infantería o Castillo de San Servando evocan principalmente recuerdos o antiguos usos del lugar respectivamente.

- ¿Conoce este lugar? Esta pregunta se ha efectuado con respecto a un listado de distintos topónimos del barrio para conocer el grado de familiaridad de la población local con su toponimia. El conocimiento o el desconocimiento de la toponimia proporciona indirectamente información sobre los usos y costumbres de los vecinos del barrio. Por ejemplo, en el barrio de Buenavista resulta muy revelador el hecho de que cerca de la mitad de los encuestados no hayan sido capaces de reconocer los topónimos de los dos principales parques urbanos del barrio, a pesar de que constituyen espacios fácilmente accesibles y se encuentran situados en el centro del barrio (fig. 11). Por el contrario, las principales avenidas del barrio han sido reconocidas prácticamente por la totalidad de los encuestados. Este hecho confirma, entre otras cuestiones, que la toponimia de las grandes avenidas se asimila mejor en el imaginario de los vecinos ${ }^{14}$.

14 Lo que, tal y como se indicaba en el epígrafe anterior en relación con los mapas mentales del barrio de Buenavista, se asocia por un lado con el hecho de que el barrio se encuentra en proceso de consolidación y, por otro lado, con el papel primordial que juegan estos nombres en los nuevos procesos urbanos globales con el cambio del modelo de habitabilidad (y sus efectos). 


\begin{tabular}{|c|c|c|c|c|c|c|c|}
\hline \multirow{8}{*}{ 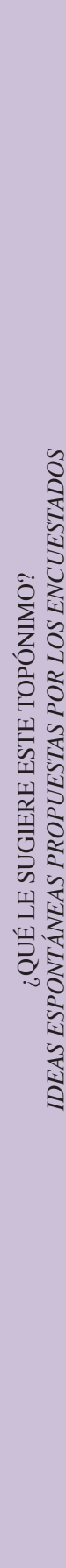 } & 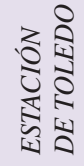 & $\sum^{\frac{1}{4}}$ & 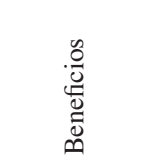 & 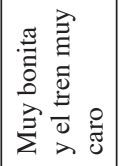 & 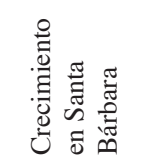 & 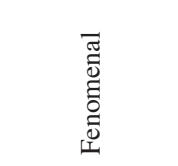 & 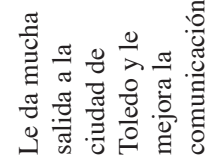 \\
\hline & 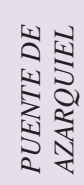 & 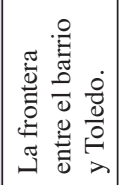 & 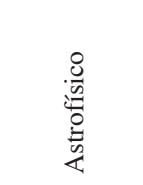 & 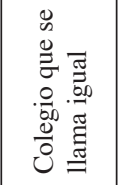 & 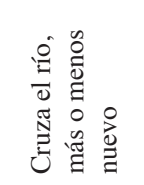 & 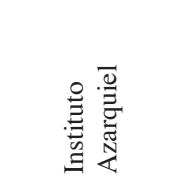 & 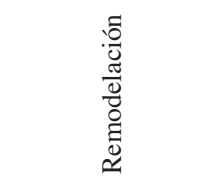 \\
\hline & 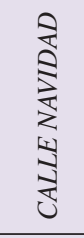 & $\begin{array}{l}\frac{\pi}{\sigma_{0}} \\
\frac{\ddot{\psi}}{<}\end{array}$ & 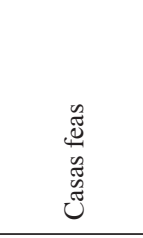 & 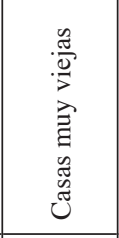 & 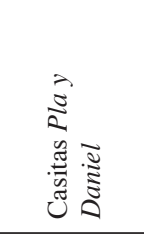 & 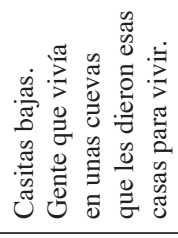 & 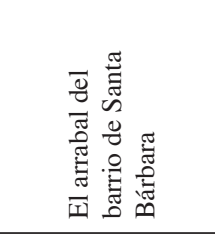 \\
\hline & 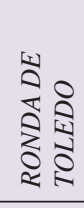 & 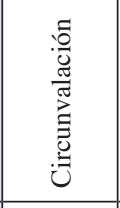 & 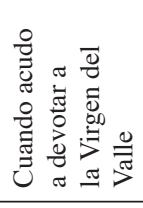 & 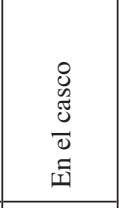 & 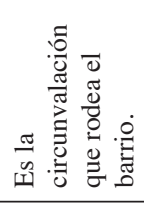 & 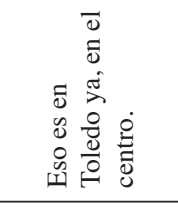 & 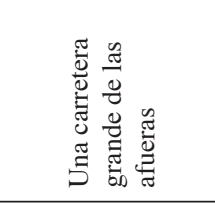 \\
\hline & 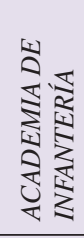 & 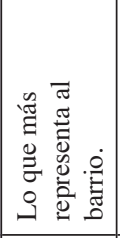 & 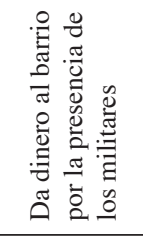 & 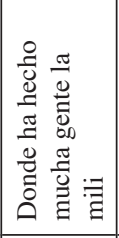 & 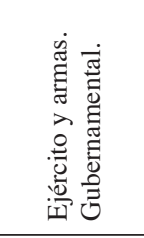 & 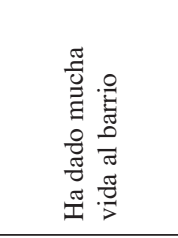 & 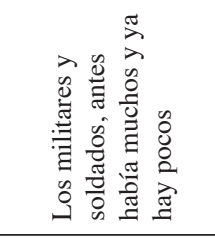 \\
\hline & 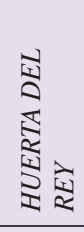 & 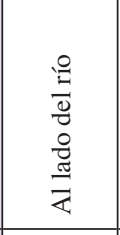 & 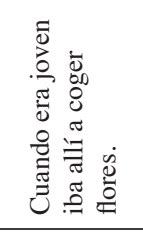 & 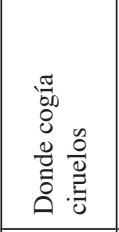 & 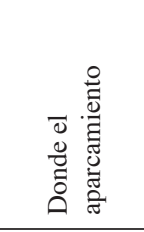 & 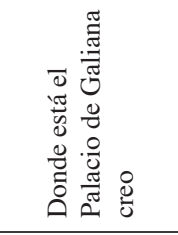 & 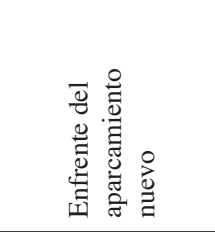 \\
\hline & 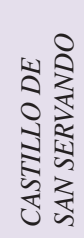 & 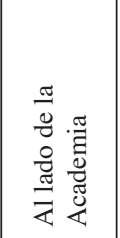 & 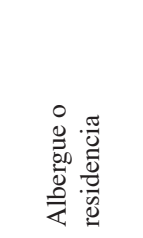 & 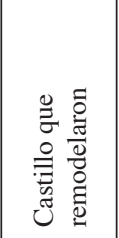 & 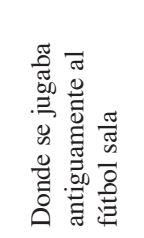 & 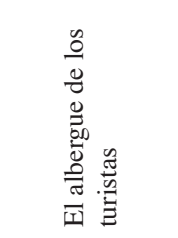 & 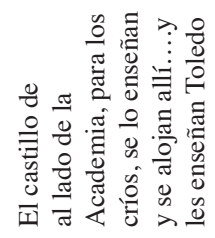 \\
\hline & 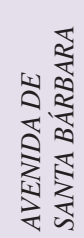 & 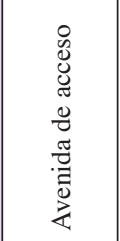 & 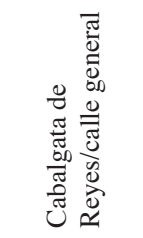 & 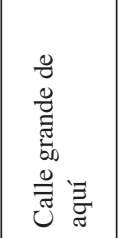 & 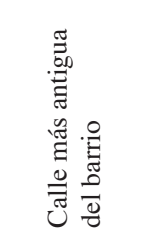 & 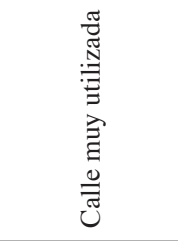 & 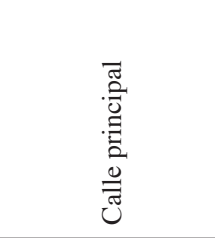 \\
\hline
\end{tabular}




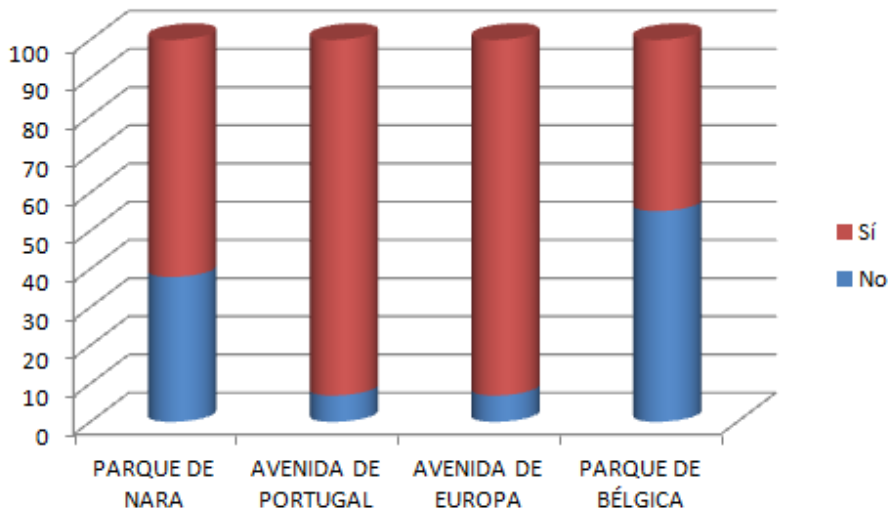

Valor porcentual. Elaboración propia a partir de encuestas de campo, noviembre de 2012.

\section{ANÁLISIS INTEGRADO DE LA TOPONIMIA URBANA}

De cara a poner de relieve la importancia que tiene la combinación de técnicas de campo en el estudio de la toponimia urbana se muestra, a continuación, un ejemplo de uso integrado de las técnicas presentadas para el caso de Toledo. El análisis del topónimo Parque de Nara, en el barrio de Buenavista, a través de la aplicación combinada de las técnicas expuestas, permite conocer diversos aspectos sobre el lugar que solo resultan perceptibles a partir de la reflexión e interpretación del topónimo.

El Parque de Nara es un parque urbano que se encuentra situado en la zona más antigua del barrio de Buenavista, cuya construcción se inició en los 70 y aún continúa, siendo uno de los barrios más modernos de Toledo ${ }^{15}$. Se trata de un parque lineal de aproximadamente 500 metros de longitud, pero de apenas 80 metros de anchura. Tiene la particularidad de que, a diferencia del resto de parques urbanos de la ciudad, no se encuentra delimitado por una valla propia, sino por los muros de distintas manzanas cerradas que disponen, cada una de ellas, de su propio acceso particular al parque (fig. 12). En este sentido, aunque se trate de un parque público, funciona en cierta medida como un gran jardín de estas urbanizaciones privadas, cuestión que queda patente tanto en las encuestas como en los mapas mentales donde, en general, solo lo mencionan y dibujan espontáneamente los vecinos de dichas edificaciones.

El análisis del topónimo permite constatar que este parque constituye un elemento referencial para los vecinos de Buenavista. En las encuestas, tanto el parque (los encuestados han tenido que identificarlo en una fotografía) como la propia denominación son más conocidos

15 El hecho de que el proceso de urbanización aún continúe también deja su impronta en la toponimia del barrio. Es posible encontrar entre las actas de los Plenos de la Junta Municipal de Distrito solicitudes de cambios de denominaciones de la toponimia del barrio y de su señalización. 
por los vecinos que otras infraestructuras y equipamientos de uso público del barrio ${ }^{16}$. El nombre Nara, tan distinto al resto de las denominaciones del barrio (eminentemente nombres de países y capitales europeas), lo hace más reconocible que otros lugares del barrio. En las respuestas recogidas, el cercano Parque de Bélgica, mucho más visible y accesible al transeúnte por localizarse en una de las principales avenidas de barrio y anunciarse con un gran cartel en su acceso principal, resulta ser una denominación mucho menos conocida. El significativo nivel de reconocimiento del topónimo Parque de Nara resulta ilustrativo de la importancia que tiene una denominación distinta a un patrón nominativo en los barrios de nueva construcción y de la importancia de los parques urbanos como referentes en la ciudad de la manzana cerrada.

El caso del Parque de Nara es también testimonio del papel que puede ejercer el topónimo, como cualquier otro elemento urbano, como símbolo de identidad. La Asociación de Vecinos Parque Nara pone de relieve a través de su propio nombre el valor que se aspira a dar a este espacio como lugar icónico del barrio (fig. 13). Por otro lado, la referencia a Nara conecta simbólicamente el parque (y, por extensión, al barrio en su conjunto) con la ciudad japonesa de Nara, con la que está hermanada Toledo, explicitando la pertenencia de este ámbito a Toledo, a pesar de que se localiza lejos del casco histórico.

PARQUE DE NARA Y LOGO DE LAASOCIACIÓN DE VECINOS PARQUE NARA
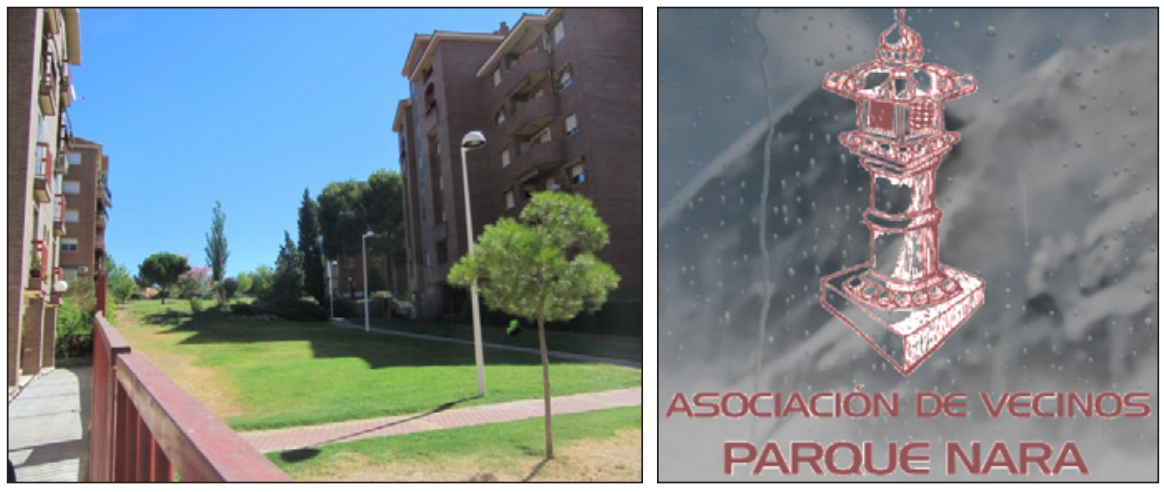

Izquierda: vista parcial del Parque de Nara. Fotografía del autor.

Derecha: el símbolo del blog de la Asociación de Vecinos Parque Nara incluye, simbólicamente, la imagen de una de las esculturas de inspiración japonesa situadas en el interior del parque. De este modo, se acentúa el valor del topónimo-símbolo como testimonio del hermanamiento de Toledo con la ciudad japonesa y, por extensión, se estimula el sentimiento de pertenencia a la ciudad de este barrio. Fuente: blog de la AAVV Parque Nara.

La observación de campo y las memorias de las derivas urbanas han permitido confirmar el papel del topónimo Parque de Nara como elemento referencial, no solo a nivel identitario, sino también funcional, puesto que constituye un verdadero punto de encuentro en el barrio (tabla 5). En este caso, las memorias confirman lo que el paisaje ya evidencia.

16 Este hecho contrasta con lo poco que se ha nombrado este parque en los mapas mentales (pese a haberse representado habitualmente), por el referido uso recurrente de topónimos genéricos (parque, estación, etc.). 


\begin{tabular}{|c|c|}
\hline Testimonios & Observaciones \\
\hline $\begin{array}{l}\text { INFORMANTE } 1 \\
\text { "Este parque divide las urbanizaciones de la Ronda } \\
\text { de Buenavista con una función más de calle verde que } \\
\text { de parque. La parte del parque de Nara más cercana al } \\
\text { comisaría de la Policía Nacional sin embargo si es más } \\
\text { usada como parque, aunque se ha conservado en su mayor } \\
\text { parte en la forma que era antes de construirse el barrio de } \\
\text { Buenavista, un campo de cultivo de olivos." } \\
\text { INFORMANTE } 2 \\
\text { "Rápidamente me di cuenta de que el parque de Nara no } \\
\text { era uno de los elementos más conocidos del barrio sino } \\
\text { el que más, decían que raro era la persona que no sabía el } \\
\text { nombre del parque. Además corresponde a un punto de } \\
\text { encuentro entre los habitantes jóvenes del barrio." } \\
\text { INFORMANTE } 4 \\
\text { "Lo que más me llamó la atención de Buenavista es el } \\
\text { Parque de Nara porque es un parque conocido y está } \\
\text { lleno de vida y de personas de todas las edades (...) da la } \\
\text { sensación de que está bastante cuidado." }\end{array}$ & $\begin{array}{l}\text { - El topónimo Parque de Nara es } \\
\text { paradigmático del carácter referencial } \\
\text { de los espacios públicos en los barrios } \\
\text { nuevos. } \\
\text { - La generación de una denominación } \\
\text { con significado simbólico (Nara, tal y } \\
\text { como se ha referido, es el nombre de } \\
\text { una de las ciudades con las que está } \\
\text { hermanada Toledo) puede facilitar su } \\
\text { asimilación y reconocimiento por parte } \\
\text { de la población local. } \\
\text { - El uso que se le da a la denominación } \\
\text { y su mayor frecuencia de uso en las } \\
\text { memorias esindicio de la consolidación } \\
\text { de este espacio público en un barrio } \\
\text { que aún se está configurando. }\end{array}$ \\
\hline
\end{tabular}

Elaboración propia a partir de ejercicio experimental con derivas urbanas, noviembre de 2013.

Por otra parte, la información territorial que contienen los topónimos puede tener un alcance turístico-funcional. Un topónimo como Parque de Nara en un barrio en desarrollo como Buenavista puede tener no solo una finalidad simbólica e identitaria, sino también un interés práctico. En este caso, la referencia a Nara puede funcionar como reclamo turístico y comercial en un barrio fundamentalmente residencial (cuadro 1).

\begin{abstract}
Toledo creará un gran jardín japonés con más de 300 cerezos en una iniciativa turística con el mercado nipón. El alcalde de Toledo, Emiliano García-Page, ha firmado un convenio de colaboración con el presidente de la Asociación Hispano-Japonesa de Turismo, Haruo Shimohira, para la creación del "Jardín de los cerezos" en el Parque de Nara como símbolo de unión de ambas culturas y que forma parte de la estrategia turística del Ayuntamiento para promocionar la ciudad en el mercado nipón. Con esta iniciativa, el Gobierno municipal pretende aumentar la oferta turística para atraer japoneses
\end{abstract}

Tal y como queda patente en la noticia, el topónimo Parque de Nara ha sido una buena excusa para promocionar el turismo japonés en el barrio. Noticia publicada en EuropaPress a 11 de enero de 2013. 
El análisis del topónimo Parque de Nara a través de la aplicación combinada de los métodos y técnicas de análisis toponímico urbano presentados proporciona, en síntesis, algunas ideas sobre el lugar que no resultan inmediatamente perceptibles:

- El topónimo Parque de Nara se presenta como testimonio del origen del barrio y su evolución. La introducción y pervivencia de este topónimo, muy diferente al resto de la toponimia del barrio, responde a una realidad distinta de la actual. Este parque se construye en los años 70, cuando Toledo iniciaba la expansión de su imagen internacional a través de la política de hermanamientos con otras ciudades (Nara entre ellas). También, marca el fin de un modelo de planeamiento concentrado en favor de otro expansivo propio de los años 80. Este nuevo modelo deja su impronta en los patrones toponímicos del resto del barrio (toponimia muy neutral propia de la promoción unitaria, que nombra en conjunto a la urbanización), donde prácticamente todas las vías urbanas y varios equipamientos públicos reciben el nombre de países europeos (Calle de Alemania, Avenida de Francia, etc.).

- El Parque de Nara constituye uno de los símbolos del barrio. Su valor diferencial respecto al resto de los topónimos del barrio y su presencia en el discurso ciudadano (como en el nombre de la asociación de vecinos) lo erigen en lugar de referencia para los vecinos a nivel espacial y de identidad.

- El topónimo (como el lugar) funciona como un elemento semiprivado. Parque de Nara hace referencia a un espacio que algunos vecinos perciben como público y colectivo, mientras que otros apenas lo utilizan o lo consideran por concebirlo como un lugar privado. Este hecho se asocia de forma directa con las transformaciones de las formas urbanas y los estilos de vida del nuevo urbanismo de manzana cerrada.

- El topónimo está facilitando la creación de un producto turístico en torno a él. A pesar de tratarse de un barrio periférico de escaso interés turístico, la conexión que establece Parque de Nara entre el barrio de Buenavista y la ciudad nipona con la que está hermanada Toledo favorece, en este caso concreto, la creación de un producto turístico orientado a los turistas japoneses ${ }^{17}$.

La combinación de técnicas toponímicas ha permitido, en este caso, plantear nueva información sobre el lugar que se encontraba codificada en el topónimo y proponer, confirmar o descartar hipótesis que se han podido plantear sobre el parque y sobre el barrio de Buenavista en su conjunto.

\section{CONCLUSIONES}

La información que contienen los topónimos más allá de la que transmiten por su condición de signos lingüísticos tiene elevado interés en el análisis geográfico. Los métodos y técnicas presentados para su recopilación y su estudio se enmarcan en el giro conceptual

17 El hecho de que el parque se denomine Parque de Nara dota de sentido a que el parque de los cerezos destinado a atraer a los turistas japoneses se instale en este barrio y no en otro lugar más céntrico. Los topónimos son una verdadera herramienta para fabricar y promocionar elementos distintivos con fines turísticos o comerciales (Shoval, 2013). 
y epistemológico que está experimentado el análisis de la toponimia urbana en los últimos tiempos ${ }^{18}$. En este sentido, los instrumentos presentados constituyen procedimientos de extracción de información asociada al topónimo en una lectura distinta de la ciudad. También, constituyen herramientas de contrastación de la información toponímica obtenida a través del análisis documental y etnográfico, el cual, en todo caso, constituye el punto de partida de cualquier análisis toponímico. La revisión y el análisis de cartografía, bibliografía y documentación actual e histórica específica resultan indispensables para conocer e interpretar cualquier topónimo, pero su combinación con la observación de campo y demás técnicas toponímicas llevan a una lectura mucho más completa o incluso nueva de la ciudad.

El valor subjetivo e incompleto que poseen en sí las técnicas consideradas al aplicarlas de forma individual, se trasforma y depura mediante un análisis crítico interrelacionado y concienzudo de la información para obtener así referencias y conclusiones de validez general, extraordinariamente útiles en el campo del significado y del criptosignificado de los topónimos. Esta inmersión en el ámbito directo y concreto del entorno del lugar, de sus habitantes y de sus percepciones permite, en cualquier caso, nutrirse de forma más directa de la extraordinaria riqueza informativa y de matices de estos ámbitos.

Cada topónimo es único y, por tanto, la información que se puede extraer de su análisis geográfico, sea este individual o de conjunto, es también siempre única. Atendiendo al carácter único e irrepetible de dicha información, cabe señalar que la toponimia requiere una permanente revisión y protección como fuente de información geográfica y como patrimonio inmaterial respectivamente. Es necesario, en este sentido, continuar avanzando en la integración del estudio de los topónimos en el análisis geográfico.

\section{REFERENCIAS}

AINIALA, T. y VUOLTEENAHO, J. (2011): Directions in Urban Place Name Research. Helsinki. Kotimaisten kielten tutkimuskeskus.

ARROYO, F. (2010): «Creciente interés geográfico por la toponimia» en Estudios Geográficos, $\mathrm{n}^{\mathrm{o}} 71$ (268), 299-309.

ARROYO, F. (2014): «Toponimia de ficción. Sobre los nombres de lugar en el imaginario colectivo» en El Poder de la Historia. Huella y legado de Javier Donézar Díez de Ulzurrun (Díaz Sánchez, P. Martínez Lillo, P. y Soto Carmona, A. Eds.). Vol. 2, 487-510. UAM Ediciones, Madrid.

BARNES, T. J., y DUNCAN, J. S. (1992): «Introduction. Writing worlds» en Writing worlds: Discourse, Text and Metaphor in the Representation of Landscape. 1-17, Routledge, London.

BERG, L. D., \& VUOLTEENAHO, J. (Eds.). (2009): Critical toponymies: The contested politics of place naming. Ashgate Publishing, Ltd.

18 La creciente diversidad de métodos en toponimia no tiene límites. A modo de ejemplo, una de las experiencias más recientes consiste en la autoinclusión del investigador en la comunidad cuyos nombres desea estudiar para hacerse partícipe de ellos (Burns, 2015), profundizando en la componente empírica de los topónimos. 
BEUCHOT, M. y COCA, J.R. (2013): «La búsqueda del sentido a través de la hermenéutica analógica. Entrevista al Dr. Mauricio Beuchot Puente» en Impacto de la Hermenéutica Analógica en las Ciencias Humanas y Sociales (Coca J.R., ed.). Primera edición, mayo de 2013. Huelva, Hergué Impresores, S.L.

BURNS, A. (2015): «Data Collection in Aberdeenshire: a Synchronic Field-name Study» en Challenges in Synchronic Toponymy-Défis de la toponymie synchronique, 55.

CERDÀ, J. (2012): «Observatorio de la transformación urbana del sonido: La ciudad como texto, derivas, mapas y cartografía sonora» En Arte y Políticas De Identidad, 7, 143-162.

DEBORD, G. (1958): «Teoría de la Deriva» en Internationale situationniste, vol. 2. Traducción extraída de Internacional situacionista, vol. I: La realización del arte, Madrid, Literatura Gris, 1999.

DIDELON, C., RUFFRAY, S., BOQUET, M. y LAMBERT, N. (2011): «A world of interstices: A fuzzy logic approach to the analysis of interpretative maps» en The Cartographic Journal, 48(2), 100-107.

DORION, H. (1984): «Les relations entre la toponymie et les autres sciences sociales» en 450 ans de noms de lieux française en Amerique du Nord. Québec, Les Publications du Québec.

DURÁN, M. Á. (1998): «La casa del lenguaje (sobre el sentido y significado en la toponimia urbana)» en Cuenta y Razón del Pensamiento Actual, 107, 31-36.

GARCÍA, F.; GALLEGO, M. y PRECEDO, A. (2002) «Proyecto toponimia de Galicia. Toponimia aplicada a la cartografía» en X Congreso de Métodos Cuantitativos, Sistemas de Información Geográfica y Teledetección, Valladolid, Universidad de Valladolid-Asociación de Geógrafos Españoles (García Cuesta, J.L., Andrés López, G. y Molina de la Torre, i. eds.).

LIGHT, D. (2014): «Tourism and toponymy: commodifying and consuming place names» en Tourism Geographies, 16(1), 141-156.

LÓPEZ, S. (2014): «Educar la mirada: El paseo, método para situarse en el mundo» en URBS. Revista De Estudios Urbanos y Ciencias Sociales, 4(1), 79-93.

LUCAS, A. M. y ORDINAS, A. (2013): «Mapes mentals, geolingüística i talassonímia en el Migjorn de Mallorca» en Scripta Nova: revista electrónica de geografía y ciencias sociales, (17), 434.

LYNCH, K. (1960): The image of the city. MIT press.

MARTÍNEZ DE PISÓN, E. (2010): «Valores e identidades» en El paisaje, valores e identidades (Martínez de Pisón, E., y Ortega, N. eds.). Fundación de Duques de Soria, Ediciones de la Universidad Autónoma de Madrid.

MARTÍNEZ-ARRARÁS, C.; ANGULO, M.T.; RABAZAS, A. y VASELINOVA, D. (2013): «Derivas de la memoria. Una biocartografía de Madrid. Indagación en las metodologías de comprensión de la ciudad desde la experiencia subjetiva» en Arte y Ciudad, 3.1, 471-490.

MEMBRADO, J. C. (2012): «Toponimia sucronense en Valencia» en Biblio 3w: revista bibliográfica de geografía y ciencias sociales, 17.

MÉNDEZ, E., (2012): «Imaginario de ciudad turística: una propuesta de abordaje» en Topofilia, Revista de Arquitectura, Urbanismo y Ciencias Sociales, vol. II, $\mathrm{n}^{\circ} 3$. Centro de Estudios de América del Norte, El Colegio de Sonora. 
ORDINAS, A. y BINIMELIS, J. (2013): «La caracterización del paisaje de Menorca a través de la toponimia» en Investigaciones Geográficas, $\mathrm{n}^{\circ} .60$ (julio-diciembre 2013), 155-169 PELLICER, I., VIVAS-ELIAS, P., y ROJAS, J. (2013): «La observación participante y la deriva: Dos técnicas móviles para el análisis de la ciudad contemporánea. El caso de Barcelona» en EURE, 39(116), 119-139.

PILLET, F. (2004): «La geografía y las distintas acepciones del espacio geográfico» en Investigaciones geográficas, 34, 141-154.

RADDING L. y WESTERN J. (2010): «What's in a name? Linguistics, Geography and Toponyms» en Geographical Review, $n^{\circ} 100,394-412$.

RIESCO, P. (2010): «Nombres en el paisaje: la toponimia, fuente de conocimiento y aprecio del territorio» en Cuadernos geográficos de la Universidad de Granada, 46, 7-34.

RODRÍGUEZ, I. (2006): «Mecanismos de control territorial en tiempos de la globalización» en Scripta Nova. Revista electrónica de geografía y ciencias sociales. Universidad de Barcelona, 1 de agosto de 2006, vol. X, núm. 218 (28).

RODRÍGUEZ, A (2012): «Ciudades del turismo, imaginarios y topónimos» en Topofilia Revista de Arquitectura, Urbanismo y Ciencias Sociales, vol. IV, $\mathrm{n}^{\circ} 1$. Centro de Estudios de América del Norte, El Colegio de Sonora.

RODRÍGUEZ, A. y VÁZQUEZ, A. (2013): «Nuevas tendencias el análisis y el tratamiento de la toponimia en el marco de las Infraestructuras de Datos Espaciales» en Jornadas Ibéricas de Infraestructuras de Datos Espaciales. Toledo, 14 de noviembre de 2013.

ROSE-REDWOOD, R., ALDERMAN, D., y AZARYAHU, M. (2010): «Geographies of toponymic inscription: new directions in critical place-name studies» en Progress in Human Geography, 34(4), 453-470.

SHOVAL, N. (2013): «Street-naming, tourism development and cultural conflict: the case of the Old City of Acre/Akko/Akka» en Transactions of the Institute of British Geographers, 38(4), 612-626.

TORT, J. (1999): Els noms de lloc i el territori. Una interpretació geogràfica de la toponímia del Baix Camp (Tarragona). Tesis doctoral. Universitat de Barcelona, Barcelona.

TORT, J. (2001): «La toponímia com a camp de coneixement interdisciplinari: algunes bases teòriques i epistemològiques per a l>estudi dels noms de lloc» en Scripta Nova: revista electrónica de geografía y ciencias sociales, $5,86$.

TORT, J. (2003): «Toponimia y marginalidad geográfica: Los nombres de lugar como reflejo de una interpretación del espacio» en Scripta Nova: revista electrónica de geografía y ciencias sociales, $7,138$.

TUAN, Y. (1974): Topophilia. A study of environmental perception, attitudes and values. Prentice-Hall Inc., Englewood Cliffs, Nueva Jersey.

UNGEGN (Grupo de Expertos de las Naciones Unidas en Nombres Geográficos) (2011): «Resolutions Adopted at the Nine United Nations Conferences on the Standardization of Geographical Names 1967, 1972, 1977, 1982, 1987, 1992, 1998, 2002, 2007» en 26th Session of the United Nations Group of Experts on Geographical Names.

WOODMAN, P. (2012): «Toponymic expression: endonyms and exonyms in speech, writing and reading» en The Great Toponymic Divide. Reflections on the definition and usage of endonyms and exonyms (Woodman, P. ed.). Bernardinum publishing house. Warszawa, 2012. 